\title{
Sequence Types and Textual Production Teaching
}

\author{
Gisele Gomes Guedes, Xella Ohana da Cunha do Nascimento \\ Rural Federal University of Rio de Janeiro, Seropédica, Brazil
}

\begin{abstract}
Currently, Portuguese teaching prioritizes the study of text sequence types and genres. All the didactic material and activity in the classroom are guided by this study. Because the narrative text type is one of the first which the student has contact with, it will be the focus of this work. This article aims to present a didactic sequence along the lines of Dolz, Noverraz, and Schneuwly (2004), using the fable and tale genres in order to contribute to the development and appropriation, by the students, of the structural and linguistic characteristics of these genres and the type that makes it up. This sequence of activities is fundamental to work with text production, as it greatly contributes to the writing teaching.
\end{abstract}

Keywords: sequence types, text genres, writing

\section{Introduction}

The teaching of textual production still takes place unsystematically in many classrooms. Although the production of texts in written form is more worked than in oral form, it is clear that the teaching of writing still is devoid of an organizational didactic treatment.

Knowing that the sequence types are more general and broad forms covering certain text organization features (as Adam) they should be presented and worked with students from significant text genres for them.

The textual genres are varied types of textual statements that exist for social and actual everyday use as a communication tool, such as a recipe, a list, a tale, and a story. Many of these genres are composed of one or more text types: narrative, descriptive, argumentative, expository, or injunctive.

In view of the knowledge organization of the texts by text types and their presence in the various kinds of social function, we cannot find that the student will learn naturally how to produce these multiple writing genres. The students need to identify the organizational plan of the text types, differentiating between genres that are part of their daily lives and be able to produce them according to necessity and purpose.

Therefore, it is necessary that the teaching of textual production happens systematically, around a text genre, from organized activities in Portuguese classes.

This paper presents the concepts and studies of sequence types and the work with textual genres. Since the teaching of textual production requires advances in its practice, the studies on the subject will help to think of ways to structure this teaching. At the end, some suggestions for school activities for a certain sequence types will be presented.

Gisele Gomes Guedes, master-Profletras UFRRJ, teacher of the 2nd Segment of Elementary Education, Education Department, Rural Federal University of Rio de Janeiro.

Xella Ohana da Cunha do Nascimento, master-Profletras UFRRJ, teacher of the 1st and 2nd Segments of Elementary Education, Education Department, Rural Federal University of Rio de Janeiro. 


\section{Text Genres and Sequence Types}

Reading and understanding of a text will be skills acquired by students in a successful way as the text to be considered as a meaningful whole, identifying which genre owned and also textual typology that is prevalent in its construction. The understanding of the used linguistic strategies and its relation to genre and the type make possible a reflection on the language and an understanding of the constitution of the text, causing an interaction among reading, text production, and linguistic analysis as set out in the National Curricular Parameters (PCN). ${ }^{1}$

Starting from this assumption, it is believed that teaching of textual production will become more efficient if students manage to understand how each genre is constituted and what the characteristics of each type predominate in each.

When speaking of education, the concept of genre is important, because according to Marcuschi (2008), verbal communication is only possible through a genre. Also in his book, the author defines textual genres as “...texts we encounter in our daily lives and which have typical social communicative standards defined by functional compositions, enunciation goals and styles specifically made in the integration of historical, social, institutional and technical forces" (p. 155).

The genres cannot be considered as rigid structures, but as dynamic entities. According to Bakhtin (2011), "genres are types of relatively stable statements" (p. 262). They have stability as it is possible to recognize similar characteristics in several texts, for example, when asking three different persons to write a recipe, you can see features, own of this genre, as verbs in the imperative, ingredients and method of preparation, in the three texts elaborated. But it is acceptable a certain degree of instability, because it is possible to make certain adjustments without the texts configure different genres.

Therefore, the genres have an identity and are seen as powerful entities that, in textual production, impose choices that cannot be completely free or random, either in the lexical, formal, or thematic point of view. According to the compositional aspects, they are characterized by: style, thematic content, and structure.

The style is linked to the lexical selection, common expressions and phrases and how they are organized and the degree of formality in the relationship between the speaker and the interlocutor. The thematic content is related to the subject, that is, to what can be said in that genre. The structure refers to the parts that make up each genre and text types.

When working text genres in the classroom, some aspects such as theme/intention (the text purpose), circulation (the source where the text usually circulates), interlocutors (participants of the communication situation), linguistic strategies (most common linguistic marks genre), and predominant text typology, should be considered.

When the teacher works these issues in the classroom, he will be able to help students in understanding of each genre and in the production of contextualized texts.

As it is possible to see, when speaking of genres, one should speak in text types or in sequence types, a term postulated by Adam.

By supporting the principle formulated by Bakhtin on "relatively stable types of statement", Adam (2001) provides a set of sequence types that are inserted on the basis of standard texts of our social life: narrative, descriptive, argumentative, explanatory, and dialogical. It is noteworthy that sequence is not genre. Sequence types are,

\footnotetext{
1 This is a document that performances as a basic referential that guides teachers in the search of new approaches and methodologies (see portal.inep.gov.br/web/saeb/parametros-curriculares-nacionais).
} 
Relatively fixed segments that make up the different and vulnerable genres in our society. They are types that cut across different genres. As textual construction entities, the sequences are abstract elements because they do not exist in isolation in real life of communicative relationships, and at the same time concrete, because provides linguistic structures characteristics. But the genres are the statements of real life, laden with pragmatic, contextual and ideological conditionings. (Wachowicz, 2012)

The text sequence predicts significant parts of structuring text called macropositions that are made up of propositions or sentences. Through time and social relations, the using is being fixed and the predictability is guaranteed. The very reading and writing history begins to organize these features so that is possible to predict the structure of a narrative or a description. Therefore, it is possible to recognize in a fable, elements of a narrative sequence that will also be present in tales or novels. Such elements can be recognized even in other semiotic systems as a movie, theater, or a soap opera.

To approach types such as a synonym of text sets a mistake since the texts are organized according to the predominant type, though more than one may appear in their constitution. According to Marcuschi (2008), the genre cannot be seen as opposed to the typologies. Both should not form a dichotomy, but should be complementary and integrated. Both genres and typologies do not exist in isolation or unrelated to one another; they are, in fact, forms that constitute a text, and according to Marcuschi, "all texts perform a genre and all genres perform diverse sequence types" (Marcuschi, 2008, p. 160)

The sequence types can be defined as linguistic schemes that constitute the various genres and have a limited range in relation to social circumstances.

According to Koch (2015), from the familiarization with the textual genres, the student should be led to understand, among certain sequence types, a set of common characteristics related to structuring, linguistic elements, and deictic terms.

From the given concept, the five established sequence types and a brief explanation of them will be presented. It is noteworthy that the narrative sequence, as the focus of this work, will have a more detailed explanation.

The descriptive sequence has a less specific character, because it presents the qualities and properties of a given entity without presenting a well defined temporal organization. It has as main objective to present physical and psychological characteristics. In this sequence are prevalent adjectives, adverbs of manner and intensity and state or situation verbs in the present or past tense. Often the description may appear in other sequence types.

The explicative sequence aims the discussion, information, or exposure of a subject. It predominates here discursive operators as conjunctions and prepositions, modalizer expressions as adverbs of doubt and affirmation besides verbs in present time.

The argumentative sequences have to defend a point of view or opinion by arguments and counter-arguments organized logically, showing relations of cause and consequence. In them are prevalent discursive operators as conjunctions and prepositions, modalizer expressions, verbs that introduce opinion and argumentative operators.

The injunctive-instructional sequences are intended to provide behavioral prescriptions or actions ordered sequentially. It may also present rules and procedures that must be followed. Verbs in the imperative, in the infinitive, or in the future and pronouns, such as you, are prevalent in this sequence.

The narrative sequences aim at the report of a fact or actions in a time sequence. Language brands that stand out here are the action verbs, adverbs of time, cause and place, verbs in the present or past tense. The 
presence of direct, indirect and free indirect speeches is frequent.

The narrative structure is perhaps the most studied structure, since it is the oldest, because even when communication is only made orally, people have the habit of reporting facts and storytelling. It is possible to understand the construction and the propagating of structures that are recognized and used by people and that are being fixed over time.

Wachowicz (2012) summarizes some criteria formulated by Adam, which are used to compose a narrative sequence.

A narrative sequence has a flow of events in time, which remains a theme through actions transformations in a causal relationship, in other words, it takes different events arranged in a time sequence, but they should converge to a single theme and the actions should have a causal relationship with each other.

It should exist, at least, one anthropomorphic character involved in the events. Such characters are those with human representation; even if animals or objects, they have a human behavior printed by narrative text.

It is necessary to have a conflict or complication that forwards to a resolution. In the narrative not only a succession of events occurs, but also it is necessary that they be organized for the culmination of a conflict that will ensure the drama to the characters.

A narrative sequence can present a value judgment or an opinion; in other words, a final evaluation. This may be implicit or explicit (as in fables) and assumes that, for every text there is an interlocutor. Therefore, "any statement is directed to another: as a response, agreement or assessment" (Wachowicz, 2012, p. 57).

The trace of verisimilitude must be present since this factor provides the narrative trace of fiction. In other words, to the listener/reader what is being narrated does not need to be real, just be possible to happen.

In school practice, the elements of a narrative are presented to students as it follows: presence of an initial situation in which there will be the presentation of characters and their situation in time and place; a complication or conflict that will initiate a series of actions; the climax is the moment of greatest tension of history and already making a preparation for the outcome; and the outcome will be the resolution of the complication.

\section{Text Production at Schools}

When thinking about the teaching of textual production, it is clear that there is a process of change in the treatment of the texts produced by the students. The exchange itself of the nomenclature for writing to textual production can be considered the first step of this change. School writing is treated as another genre and the term production already incorporates the idea of creating, building, and carrying a more positive meaning and more associated with the idea of process, which in fact, is like writing must be seen. Furthermore, the term "textual" emphasizes the idea that the text is the subject unit which is part of and for which it is intended.

The traditional practice treats the texts produced by the students as mere essays, becoming a frustrating activity for both the student and the teacher. The student used to write only for the teacher, who was the only reader and also the evaluator, correcting the text and giving him a grade. The teacher, therefore, becomes disappointed to see that the texts presented are poorly drafted and their suggestions were ignored, realizing that the student throw the text away without even reading it.

As a reaction to this traditional practice, the interaction between the students and the teacher became enriched making learning to stay focused on the student giving him opportunities for the development of their individuality. 
It is necessary that the teacher make the student aware that writing is part of everyday life, is a tool for communication, and it is also an instrument for the creation of identity. In summary, a practice is a written language in use situations.

To adapt the textual production teaching to the sequence types becomes relevant as such sequences are language schemes that define a text organization mode. As a defined number of categories, genres will be classified according to their common characteristics inside them.

Assuming that writing is seen as a process, several steps should be considered in order to get to the final production of a text.

In the preparation will be presented not only the chosen genre but also the analysis of the structure and the type to which it belongs. Here it is the part in which is made the discussion of the allocation to be given to this production. It is important to establish a target for the texts produced in the classroom and have students become aware of it. In order to establish purpose for the elaborated texts, it can be produced anthologies, newspapers, small books, publications in newspapers and magazines of the town if it exists, on blogs and/or social networks such as facebook pages, twitter; and even provide events at the school for reading and presentation of these texts. Moreover, it is this stage that instrumentalizes the students through contacts with different texts genres on the chosen type.

The prewriting shows activities that will help in the discovery of ways to perform tasks such as collecting information or even the brainstorming. The text of the planning can be done through a script that is intended to outline what elements of the chosen type will be presented and how they are organized.

The first production will be the basis for the teacher can guide the students; and post-writing review, he can evaluate what needs to be improved.

The evaluation process is the final stage of the textual production process and it can be divided into two parts: one to be done with the students that will do a self-assessment based on criteria previously established with them; another to be done by the teacher that will create some codes that will work as a guide for rewriting.

\section{Didactic Sequences}

Yet, it is still possible to see that the teaching textual production is done in an unsystematic and improvised way. Therefore, in order to incorporate the above-mentioned steps, a stock planning is essential according to the concept of didactic sequences produced by Dolz, Noverraz, and Schneuwly. "Didactic sequence is a set of organized school activities, made systematically, around an oral or written genre" (Dolz, Noverraz, \& Schneuwly, 2004, p. 82).

The main objective of a didactic sequence should help the student master a genre better allowing him to tailor his writing to a given situation of communication. Didactic sequences will be divided into four phases: presentation of the situation, the first production, modules, and final production.

The presentation of the situation is the initial phase in which it is stipulated the task to be done by the students, the setting mode (oral or written), the genre, the purpose of the production, and its receiver. Here it is also made the preparation the content in which can be performed readings of the same sort of genres to provide familiarity with them.

The first production will serve as a regulator for the preparation of modules that will follow.

The modules may be different, without a set amount. They serve for the student to train enough in order to become qualified for the final production. Such modules should be created in order to account the problems 
encountered in the process and should go from the complex to the simple, returning to the complex, which is the final production.

The final production is the time in which the student will put into practice what has been learned over the sequence.

Considering the didactic sequences as a systematic practice that will help in the area of gender, the next step should be the domain of typologies. In tangent to the typologies, the domain must be understood here how to make the student able to recognize elements of a particular type in various textual genres and elaborate a text by applying such elements from a specified genre and previously worked.

\section{Suggested Activities}

The activities described below are suggestions for the text production work of typological narrative sequence. The textual genres chosen for this study were the tale and fable, since they are constituted and organized in their formation basically by the narrative typology. The tale is the genre of the text production proposal.

The preparation of these activities was carried out in view classes of sixth and seventh grades. It was decided to separate the activities in steps whose implementation should be carried out in two classes. Each "class" is recorded in schools, usually for a period of 50 minutes.

\section{Presentation of a Text With a Narrative Type (Tale)}

Deliver or design a narrative type text for students. Ask them to do a silent reading, and after the combined time for it, propose a collective reading of the text. Dictionaries should be available to clarify the meaning of any unfamiliar words. Orally, ask the students the subject of the text, who are the participants of the story, which was the initial situation, what was the problem occurred, and how it was all over.

Then, register on the blackboard some questions dealing with the events of the text, in order to verify the scope of certain skills, such as inferring implicit information from a text, finding explicit information in a text, and identifying the textual genre of the text. The students should answer the questions in the notebook.

The text suggested for this first moment is a tale; as this genre is the final product in the textual production proposal and it contains all the elements of the narrative sequence.

The writing activity should be corrected collectively, after the allotted time for their realization. This first step should use as resources: dictionaries, printed piece of paper or projector and the board.

\section{Presentation of Another Text Belonging to the Narrative Type (Fable)}

It is recommended to follow the same initial script of stage I, but now presenting a fable and some questions related to the text events in order to review the scope of the skills mentioned in step I. The students should register the answers in their notebook.

At the end of the given time, the correction of this writing activity must be made collectively, writing the answers on the blackboard. The resources used will be the same as in step I.

\section{Highlighting of the Characteristics of a Narrative Text}

Remind the texts of the previous steps and talk to the students that despite being a tale and a fable, respectively, both tell a story. The teacher must explain to them that every text or part of it, which shows a storytelling, is narrating something for the readers, so it is a narration; even though they are different genres. Then, show the students that every narrative text presents some own elements: narrator, space, characters, time, 
and plot. Then, as each element was explained, it would be noted on the board the identification of these items in the latest tale. About the plot, the teacher should explain to the students that all narrative is compounded of phases such as: (1) initial situation (moment that presents the characters, time, and place); (2) generator conflict or complication (a problem that changes the course of a story); (3) climax (moment of great tension); and (4) outcome (conflict resolution). In order to make the students identify these phases, the teacher should ask them to localize the correspondent paragraphs on the given text and register them in a printed board (as it follows below).

Table 1

Narrative Phases-Paragraphs Identification

\begin{tabular}{llc}
\hline Narrative phases & Description & Paragraphs \\
\hline Initial situation & Beginning of the narrative; moment that features characters, time, place in a situation \\
$\begin{array}{l}\text { Generator conflict } \\
\text { or complication }\end{array}$ & Complication or conflict that will initiate a series of actions \\
Climax & Moment of greatest tension in history. \\
Outcome & Final and conflict resolution \\
\hline
\end{tabular}

After completing the printed board, the teacher should explain to students that, in addition to these moments observed in the narrative, it is also possible to identify in some genres, like fable, the final evaluation, also known as moral. The resources used for this step would be the printed board, the whiteboard, and the projector (to show the text).

\section{Another Narrative Text}

Display a second tale to students on printed sheet of a paper. The teacher asks the students to read it silently. On the board, it would be exhibited some questions of text comprehension for students to respond orally. After this time, deliver the printed board with the narrative moments (identical frame to step III), so that they identify them in pairs in a stipulated time for this.

After the finished picture, the double must present their responses to confirm the identification of parts of the plot. The resources used in this phase IV will be printed sheets of paper and projector.

\section{Collective Text Production From a Photo}

Propose students to observe a projected picture and think what could be happening there. Explain to them that they write, collectively, a tale from this photo (class composition with a teacher as scribe). Plan, with the class, each element of this narrative that will be created and the moments of your plot (cardboard strips will be glued on the whiteboard with each narrative element: narrator, characters, time, space; and the plot with its division: initial situation, conflict/complication, climax, and outcome). After combining and planning these items with the class, it should be initiated the formal written of the tale. At this early point, the teacher could suggest divide the text into paragraphs according to each part of the plot (the 1st paragraph: initial situation, the 2nd paragraph: conflict, the 3rd paragraph: climax, and the 4th paragraph: outcome). After writing the text on the whiteboard (from the class ideas) and verification of possible adjustments and corrections, it should be registered by students in their own notebooks.

The materials used for this step are: a photo/image (previously chosen by the teacher), projector, and whiteboard. 


\section{Initial Production}

Select photos from newspapers and magazines that are relevant to activate "ideas" in students to create stories. The class will be divided into pairs or groups of three constituents, and the photos should be given to each group. Then the teacher will ask them to observe the pictures carefully and think about what could have happened at the time of the photo. Orally, each group will tell, in a few words, what has happened in each scene. After this moment, propose to the class that each group make a tale from the photos they received. Remind them that the text should contain the typical items of the textual genre tale. Announce them that these texts, after a review, will form a collection of class stories that will be available in the school library (and may even be combined a small class event for the exhibition of them). The texts will be collected at the end of this stage, because they will be the draft of the final version.

The features of this stage are: the pictures of newspapers and/or magazines, and the whiteboard (for any tips).

\section{Review and Rewrite of the Text}

The teacher will return, to student groups, the texts already marked with the observations and adjustments for their correction. The students will write the final version from the reflection on some points that may be listed on the whiteboard such as: structure and elements of the text according to the genre tale and clarity of ideas. It should also be delivered to group a sheet of paper for the final text writing. At the end of rewriting of the texts, they should be collected for assembling the collection of tales of the class, as well as the outreach event should be planned with the class, thus closing the sequence of activities. At this stage, they were used as a resource: the whiteboard and sheets of paper.

\section{Conclusion}

Considering the sequence types as linguistic schemes builders of a type of text organization, the student will not only be able to recognize them, but also use them after contact with the actual use of these structures in textual genres, as are intentional socio-historical productions.

Thus, the teaching of textual production, suggested in this study, had as starting point the textual genres run through the sequence types in focus: the narrative. Moreover, the used genres were close and meaningful to the target audience, which had some variability in their organization, but communed the same typological structural features.

To be successful in learning of textual production, as discussed in this paper, it is very important the organization and the systematization of this teaching. Aiming the text produced by the student as a final product, the preparation and the training of the student to perform this type of activity, some steps are required, since learning of textual writing does not occur naturally. Thus, the didactic sequence is the choice as a guideline in the planning of the suggested activities.

The teaching of textual production, if done in an organized and systematic way from a textual genre in which are identified the typological characteristic sequence, the situation of interaction and the purpose, provides the students with grants that will be used directly in its textual creation, and provides the teacher effectiveness in their work. 


\section{References}

Adam, J. (2001). Les Texts: types et prototypes (Texts: Types and prototypes). Paris: Nathan Université.

Bakhtin, M. (1992). A esthetics of verbal creation. São Paulo: Martins Fontes.

Ministry of Education and Culture. (1998). National curricular parameters (PCN). Brasília: MEC/SEF.

Dolz, J., Noverraz, M., \& Schneuwly, B. (2004). Didactic sequences for oral and written mode: A procedure presentation. In B. Schneuwly and J. Dolz (Eds.), Oral and written genres at school (pp. 81-108). Campinas: Mercado das Letras.

Geraldi, J. (Org.). (2012). The text in the classroom. São Paulo: Anglo.

Koch, I., \& Elias, V. (2015). Reading and writing: Text production strategies. São Paulo: Contexto.

Marcuschi, L. (2008). Text production, text genres analysis and comprehension. São Paulo: Parábola Editorial.

Santos, L., Riche, R., \& Teixeira, C. (2012). Analysis and text productions. São Paulo: Contexto.

Wachowicz, T. (2012). Linguistic analysis in the text genres. São Paulo: Saraiva. 